\title{
PREDICTION OF THE NEED FOR POSTOPERATIVE MECHANICAL VENTILATION IN MYASTHENIA GRAVIS: THYMECTOMY COMPARED TO OTHER SURGICAL PROCEDURES
}

\author{
Raymer P. Grant and Leonard C. Jenkins
}

\begin{abstract}
In a recent report Leventhal, Orkin, and Hirsh" described a scoring system felt to be of value in predicting the need for postoperative mechanical ventilation in patients with myasthenia gravis undergoing thymectomy. Leventhal, et al. identified four risk factors felt to have predictive value, namely: (1) duration of myasthenia gravis $\geq 6$ years, (2) chronic respiratory disease, (3) dose of pyridostigmine $\geq 750 \mathrm{mg}$ per day, and (4) vital capacity $\leq 2.9$ litres.

Forty-six patients with myasthenia gravis who received 68 general anaesthetics were studied retrospectively. They represented the past 10 years' anaesthetic experience with myasthenia gravis at the Vancouver General Hospital. The patients were divided into two groups: (1) those who underwent thymectomy, and (2) those who underwent procedures other than thymectomy. Using the risk factors of Leventhal, et al., a predictive score was assessed for each patient; the time to postoperative tracheal extubation was also noted for each patient.

From this study it was concluded that the scoring system proposed by Leventhal, et al. may have been of some value in predicting whether or not a particular patient undergoing thymectomy was likely to need ventilation postoperatively. In 41 myasthenics who had procedures other than thymectomy, however, this scoring system was found to be of no value.
\end{abstract}

KEY WORDS: COMPLICATIONS, myasthenia gravis; VentILATION, postoperative.

MYASTHENIA GRAVIS is not a common disorder. The world-wide prevalence is estimated at 1 per 20,000 population with an incidence of $2-5$ per $1,000,000$ population per year. Overall, women are affected twice as frequently as men; before age 30 the female to male ratio is $4.5: 1$, whereas when the disorder occurs after the age of 40 there is a slight male preponderance..$^{1,2}$

A 1,000 bed hospital admits an average of 25 patients per year with myasthenia gravis. At the Vancouver General Hospital, which has an annual surgical case load of 30,000 patients per year, only 75 anaesthetics were administered to myasthenics over a 10 year period. Myasthenia gravis thus remains a relatively rare anaesthetic management problem, but it is nonetheless a disorder of particular interest to many anaesthetists in that it directly involves the neuromuscular junction, the function of which is altered routine-

Raymer P. Grant, B.Sc., M.D.; and Leonard C. Jenkins, B.A., M.D., C.M., F.R.C.P.(C), Department of Anaesthesia, Vancouver General Hospital and the University of British Columbia, Vancouver, B.C., Canada V5Z $1 \mathrm{M} 7$.

Can. Anaesth. Soc. J., vol. 29, no. 2, March 1982 ly in the practice of modern anaesthesia. Several recent articles review the autoimmune pathophysiology of myasthenia gravis, as well as the clinical features, diagnostic tests, medical, surgical, and anaesthetic management of this interesting disease..$^{3-10}$

In a recent report, ${ }^{11}$ Leventhal, Orkin and Hirsh described a preoperative scoring system felt to be useful in predicting the need for postoperative mechanical ventilation in myasthenics undergoing thymectomy. They retrospectively identified four key risk factors: (1) duration of myasthenia gravis $\geq 6$ years ( 12 points); (2) chronic respiratory disease other than respiratory problems directly due to myasthenia gravis (10 points); (3) dose of pyridostigmine $\geq 750 \mathrm{mg}$ per day 48 hours before operation ( 8 points); (4) vital capacity $\leq 2.91$ (4 points). These risk factors were weighted according to predictive significance; as predictive total score of $\geq 10$ points identified those patients likely to need ventilation for more than 18 hours postoperatively.

The Leventhal, et al. model was correct in 91 
per cent of their cases ( 24 patients total) with no patients being falsely predicted to be ready for extubation and two patients out of 24 incorrectly predicted to need postoperative ventilation when they proved in fact to be readily extubated at the end of operation.

In this study we reviewed the anaesthetic experience in patients with myasthenia gravis at Vancouver General Hospital for the past 10 years and compared our findings in patients undergoing thymectomy with those of Leventhal, et al. We were interested to know if Leventhal's scoring system would have correctly predicted the need for postoperative mechanical ventilation in our thymectomy patients. We were further interested in reviewing our experience with myasthenics who underwent operations other than thymectomy to see which patients, if any, needed postoperative ventilation and whether or not the need for ventilatory support might have been predicted by Leventhal's scoring system

\section{Methods and Patient Characteristics}

The charts of all patients who had an admission or discharge diagnosis of myasthenia gravis during the period 1970 to 1980 inclusive were reviewed. From the charts of those patients who had a surgical operation during any of their hospital admissions, the following information was obtained: patient's age, sex, type of operative procedure, type of anaesthetic (inhalational, balanced, or regional), duration of anaesthesia and duration of tracheal intubation and ventilation postoperatively. Unfortunately, it was frequently not readily apparent what criteria were used by the attending anaesthetist in deciding whether or not a patient "needed" ventilation after operation. Arterial blood gases were recorded in virtually all cases, but other tests of respiratory function except vital capacity in a few cases were not measured, or were not documented postoperatively. The authors had to assume that each patient was extubated on the basis of clinical and laboratory parameters as soon as spontaneous ventilation was judged to be adequate.

In each case the patient's pre-operative "score" was calculated based on those predictive factors identified by Leventhal, et al. Information regarding duration of myasthenia gravis and preoperative dose of pyridostigmine (items (1) and (3) above) was available in all cases. Ten points for the presence of chronic lung disease other than respiratory problems directly due to myasthenia gravis (item (2) above) were assigned only to those patients who had an admission or discharge diagnosis of chronic obstructive pulmonary disease made by the attending physician. Finally, vital capacity was assumed to be $\geq 3.0$ litres (i.e., 0 points) in all patients who did not have documented pulmonary function tests carried out. Thus if information pertaining to items (2) and (4) in Leventhal's scoring system was not clearly documented, then the patient was not assigned any points for these variables in calculating the predictive scores.

There were 46 patients with well documented myasthenia gravis who received a total of 68 general anaesthetics during the study period; an additional six patients who had regional anaesthetics were not included in the review. Patient characteristics, predictive scores, duration of anaesthesia and time to tracheal extubation are summarized in Table I ( 27 patients who received general anaesthesia for thymectomy) and Table II (28 patients who received general anaesthesia for a total of 41 operations other than thymectomy); nine of these 28 patients underwent thymectomy during the study period and thus appear in both groups.

In the thymectomy group the mean duration of myasthenia gravis was 23 months and the mean dose of pyridostigmine was $350 \mathrm{mg}$ per day; the mean age was 35 years and there were 9 male and 18 female patients in the series. Ten patients had Osserman classification ${ }^{5}$ Class II(a) (mild generalized), 15 had Class II(b) (moderate generalized) and two had Class III (acute fulminating) myasthenia. Four patients underwent transcervical thymectomy and 23 had partial sternotomy to the 3 rd or 4 th intercostal spaces. All patients but three received halothane, nitrous oxide,

TABLE I

Thymectomy Group Patient Characteristics and PRedictive SCORES

\begin{tabular}{lc}
\hline \hline$n_{\text {total }}$ & 27 \\
Male/female & $9 / 18$ \\
Age (mean and range) & $35(17-64)$ \\
Duration of anaesthesia & 150 minutes (100-240) \\
$\quad$ (mean and range) & \\
nscore $\geq 10$ & 6 \\
$\quad$ Needed ventilation & 3 \\
$\quad$ Extubated early & 3 \\
nscore $<10$ & 21 \\
$\quad$ Needed ventilation & 4 \\
$\quad$ Extubated early & 17 \\
\hline
\end{tabular}


oxygen with or without narcotic anaesthesia; the remaining three patients received nitrous oxide, oxygen, narcotic anaesthesia. Ten patients received succinylcholine for tracheal intubation and five received d-tubocurarine.

The non-thymectomy group included 9 males and 18 females who received a total of 11 and 30 anaesthetics, respectively. The mean age was 40 years, with a range of 25-64 years. The mean duration of myasthenia gravis was much longer than in the thymectomy group, being 100 months. The average dose of pyridostigmine was $375 \mathrm{mg}$ per day. Six patients had purely ocular myasthenia (Class I, Osserman ${ }^{5}$ ), 20 had II(a), 12 had II(b), and 9 had Class IV (late, severe) myasthenia gravis. Thirty-two patients received halothane, nitrous oxide, oxygen with or without narcotic anaesthesia, and 16 received nitrous oxide, oxygen, narcotic anaesthesia. Of the patients who had the trachea intubated, 24 in all, eight received succinylcholine and six received d-tubocurarine. (In both the thymectomy and non-thymectomy patients, those who received neuromuscular blocking agents tended to be in the earlier years of the series; in the last three to five years it has been usual practice to avoid neuromuscular blocking agents in patients with myasthenia gravis). Seven general anaesthetics administered to two patients maintained on plasmapheresis were of interest in this series. The anaesthetic implications of plasmapheresis, which include documented decreases in plasma cholinesterase levels and prolonged paralysis following usual doses of succinylcholine, are reported elsewhere. ${ }^{12,13}$

Only five patients in the non-thymectomy group underwent what could be considered major surgical procedures (Table II). Nonetheless, more than half of all patients had the trachea intubated. Thirty-one of the non-thymectomy cases had undergone previous thymectomy and only one of these had required mechanical ventilation after thymectomy.

\section{RESULTS}

Our results indicate that the scoring system of Leventhal, et al. could have been of some value in predicting the need for post-operative ventilation in our patients who underwent thymectomy. Seventeen out of 20 were correctly predicted not to require post-operative ventilatory support and three were correctly predicted to need ventilation. Four patients who would have been predicted not to need ventilation, however, did in fact need IPPV for 18 hours or more. In one of these cases the patient's marked obesity was felt to be a major factor in prolonging the need for IPPV. A second patient whose need for postoperative ventilation was not correctly predicted had received a small total dose $(3 \mathrm{mg}$ ) of d-tubocurarine. (None of Leventhal's patients received muscle relaxants.) The remaining two patients had predictive scores of zero (one had a thymoma) but required ventilation for 23 hours and 17 days, respectively.

There were, therefore, seven patients who were ventilated for more than 18 hours postoperatively, only three of whom would have been correctly predicted to fall into this category. As mentioned above, two of the four patients incorrectly predicted not to need ventilation post-operatively had other factors which may have contributed to their respiratory failure.

Although Leventhal's scoring system correctly identified the majority of our patients who did not need ventilation post-operatively (17 out or 20 ), one is, of course, most interested in identifying those patients who are likely to need ventilation and in our small series only three out of five would have been correctly identified.

Three patients who had scores $\geq 10$ were, in fact, readily extubated within two hours of operation, resulting in approximately a 10 per cent "false positive" prediction rate. This was the same as in Leventhal's series.

Our results in the non-thymectomy group, however, are quite different. As can be seen in Table II, 66 per cent of patients ( 27 out of 41 ) had a score $\geq 10$. Of the 27 patients in this group, 11 were intubated and none of these required ventilation post-operatively. In fact, all patients who were intubated in the non-thymectomy group were extubated within a maximum of 90 minutes after operation. Again, it is assumed that the decision to extubate a patient was based on the presence of clinical and laboratory criteria of adequate ventilation in both thymectomy and non-thymectomy cases.

\section{Discussion AND CONClusions}

Although our review is subject to all the limitations of a retrospective study, as well as lack of full documentation in some cases, we feel that some observations can be made.

It would seem that the scoring system proposed by Leventhal, Orkin and Hirsh might have been of some value in our patients with myasthenia gravis who underwent thymectomy. Sev- 
TABLE II

Procedures other than Thymectomy Patient Characteristics and Predictive Scores

\begin{tabular}{|c|c|c|c|c|c|c|}
\hline & $\mathrm{n}$ & $\mathrm{M} / \mathrm{F}$ & Age & nintubated & Score $\geq 10$ & $T_{\text {anaes. }}$ \\
\hline Laparotomy-thoracotomy & 4 & $2 / 2$ & $\begin{array}{c}58 \\
(44-68)\end{array}$ & 4 & $\begin{array}{c}2 \\
(50 \%)\end{array}$ & $\begin{array}{c}154 \\
(120-180)\end{array}$ \\
\hline Caesarian section & 1 & $0 / 1$ & 23 & 1 & $\begin{array}{c}1 \\
(100 \%)\end{array}$ & 90 \\
\hline Minor Gen. Surgery & 7 & $4 / 3$ & $\begin{array}{c}43 \\
(22-65)\end{array}$ & 2 & $\begin{array}{c}5 \\
(70 \%)\end{array}$ & $\begin{array}{c}50 \\
(20-120)\end{array}$ \\
\hline Minor GU & 11 & $2 / 9$ & $\begin{array}{c}45 \\
(25-64)\end{array}$ & 5 & $\begin{array}{c}6 \\
(55 \%)\end{array}$ & $\begin{array}{c}45 \\
(15-120)\end{array}$ \\
\hline EENT & 11 & $2 / 9$ & $\begin{array}{c}42 \\
(22-81)\end{array}$ & 9 & $\begin{array}{c}5 \\
(45 \%)\end{array}$ & $\begin{array}{c}49 \\
(15-120)\end{array}$ \\
\hline Periph. vascular & 7 & $1 / 6$ & $\begin{array}{c}27 \\
(26-29)\end{array}$ & $1^{*}$ & $\begin{array}{c}7 \\
(100 \%)\end{array}$ & $\begin{array}{c}105 \\
(45-165)\end{array}$ \\
\hline Totals & 41 & $11 / 30$ & $\begin{array}{c}40 \\
(22-81)\end{array}$ & $\begin{array}{c}24 \\
(58 \%)\end{array}$ & $\begin{array}{c}27 \\
(66 \%)\end{array}$ & $\begin{array}{c}77 \\
(15-210)\end{array}$ \\
\hline
\end{tabular}

*One female patient with permanent tracheostomy underwent six procedures.

enteen out of 20 patients were correctly predicted to be readily extubated at the end of the operation; but only three out of seven patients were correctly predicted to need ventilation. In the study by Leventhal, et al. only false positive predictions were made; that is to say no patients were predicted to be extubatable when, in fact, they proved to need ventilatory support. Leventhal's patients were, however, managed in a more standardized fashion than our own; for example no patients received any type of muscle relaxant and their patients' respiratory function was assessed post-operatively and followed according to a well defined protocol. Our patients who underwent thymectomy were managed according to the preferences of each attending anaesthetist.

Given the small number of our patients who needed ventilation, we do not feel that we can draw firm conclusions about the usefulness of Leventhal's scoring system for patients undergoing thymectomy. We would suggest, however, that Leventhal's scoring system does not appear to be reliable in myasthenics undergoing operations other than thymectomy. Of the 24 patients in our non-thymectomy group who received endotracheal general anaesthesia, 11 had scores $\geq 10$ and yet all had adequate spontaneous ventilation at the end of the operation. Overall, 27 out of 41 (66 per cent) of our patients who received a general anaesthetic had scores $\geq 10$ and yet none of these patients had any documented respiratory difficulties post-operatively. (This observation came as something of a surprise to us.) Of those patients who were intu- bated, all were extubated within 90 minutes of the end of the operation.

The thymectomy and non-thymectomy groups were clinically comparable except that the patients who had operations other than thymectomy had had myasthenia gravis for much longer, on average, than the thymectomy group.

Of the large number of our non-thymectomy patients who had scores $\geq 10$, it must be noted that the majority underwent relatively minor surgical procedures (Table II). Duration and extent of surgery can, of course, be important factors in determining the need for post-operative mechanical ventilation in all patients, not just those with myasthenia.

\section{SUMmaRY}

Forty-six patients with myasthemia gravis who received a total of 68 general anaesthetics were studied retrospectively. The patients were divided into two groups-those who had thymectomy and those who had another surgical procedure. The two groups were clinically comparable.

The usefulness of a scoring system described by Leventhal, Orkin and Hirsh, proposed as a means of predicting the need for mechanical ventilation after thymectomy, was assessed in both patient groups. The scoring system of Leventhal, et al. is based on the presence or absence of four risk factors: (1) duration of myasthenia for longer than six years, (2) chronic respiratory disease, (3) dose of pyridostigmine 
$\geq 750 \mathrm{mg}$ per day, and (4) vital capacity less than 2.9 litres.

In each of our patients a predictive score according to the above criteria was assigned and the post-operative duration of mechanical ventilation was noted.

In the thymectomy group 17 out of 20 patients were correctly predicted not to need ventilation after operation. Of the seven patients who needed ventilatory assistance for more than 18 hours after operation only three were identified correctly.

There were 40 patients in the non-thymectomy group, 27 of whom (66 per cent) would have been incorrectly predicted to need postoperative ventilation if the scoring system of Leventhal, et al. was applicable. In fact, none of the patients in the non-thymectomy group required ventilatory support after operation.

Firm conclusions could not be drawn from the retrospective data regarding the usefulness of the Leventhal, et al. scoring system in our patients who underwent thymectomy. It is concluded, however, that the scoring system should not be used in attempting to predict the need for post-operative mechanical ventilation in patients with myasthenia gravis having surgical procedures other than thymectomy.

\section{REFERENCES}

1. Simpson, J.A. Myasthenia gravis: a personal view of pathogenesis and mechanism. Muscle \& Nerve 1: 45-56 (1978).
2. Ibid. Muscle \& Nerve $1: 151-156$ (1978).

3. ELIAS, S.B. \& APPEL, S.H. Current concepts of pathogenesis and treatment of myasthenia gravis. Med. Clin. N. Am. 63: 745-757 (1979).

4. Patten, B.M. Myasthenia gravis: review of diagnosis and management. Muscle \& Nerve 1 : 190-205 (1978).

5. Osserman, K.E. \& Genkins, G. Studies in myasthenia gravis: review of twenty year experience in over 1200 patients. Mt. Sinai Jour. Med. 38: 497-537 (1971).

6. Drachman, D.B. Myasthenia gravis. N. Eng. Jour. Med. 298: 136-142 (1978).

7. Ibid. N. Eng. Jour. Med. 298: 186-193 (1978).

8. NewsCom-Davis, J., Vincent, A., Wilson, S.G. \& WARD, C.D. Long term effects of repeated plasma exchange in myasthenia gravis. Lancet $i$ : 464-468 (1979).

9. Girnar, D.S. \& Weinreich, A.I. Anesthesia for transcervical thymectomy in myasthenia gravis. Anesth. Analg. 55: 13-17 (1976).

10. Rolbin, S.H., Levinson, G., Schnider, S.M. \& WRIGHT, R.G. Anesthetic considerations for myasthenia gravis and pregnancy. Anesth. Analg. 57: 441-447 (1978).

11. Leventhal, S.R., ORKIN, F.K. \& Hirsh, R.A. Prediction of the need for post-operative mechanical ventilation in myasthenia gravis. Anesthesiology 53: 26-30 (1980).

12. Lumley, J. Prolongation of suxamethonium following plasma exchange. Brit. Jour. Anaes. 52: $1149-1150(1980)$.

13. Patterson, J.L., Walsh, E.S. \& Hall, G.M. Progressive depletion of plasma cholinesterase during daily plasma exchange. Brit. Med. Jour. 2: 580 (1979).

\section{RÉSUME}

Récemment Leventhal, Orkin et Hirsh ont décrit un système d'indices pouvant prédire la nécessité de la ventilation post-thymectomie chez les myasthéniques. Leventhal et ses collaborateurs ont identifié quatre facteurs de risque à valeur prédictive qui sont (1) une évolution de la maladie de six ans ou plus, (2) une pathologie respiratoire chronique, (3) une dose de pyridostigmine de $750 \mathrm{mg}$ ou plus et (4) une capacité vitale de 2.9 litres ou moins.

Quarante six myasthéniques qui avaient subis un total de 68 anesthésies générales ont porté sur cette étude rétrospective. Ils représentaient l'incidence des dix dernières années de myasthénie grave au Vancouver General Hospital. Les malades ont été répartis en deux groupes: les thymectominsés et ceux qui ont subis une intervention autre que la thymectomie. En utilisant les facteurs de risque de Leventhal et collaborateurs, on a attribué à chaque malade un indice prédictif: l'intervalle requis pour l'extubation post-opératoire a aussi été noté pour chaque malade.

Cette étude permet de conclure que le système proposé par Leventhal peut être utile lorsqu'on veut prédire si un malade aura besoin ou non de ventilation après une thymectomie. Cependant, pour les interventions autres que la thymectomie, on n'a pu démontrer de valeur au système étudié. 